\title{
ANALISIS PENENTUAN GROUND SUPPORT RECOMMENDATION DECLINE CIKONENG UNDERGROUND GOLD MINE KEBUPATEN PANDEGLANG PROVINSI BANTEN
}

\author{
Abd. Rahim \\ Teknik Pertambangan Politeknik Amammapare Timika \\ abd.rahim907@yahoo.com
}

\begin{abstract}
ABSTRAK
Geoteknik tambang bawah tanah merupakan salah satu cara untuk menganalisa kestabilan lubang bukaan tambang bawah tanah dalam menentukan sistem penyangga dan membahas sistem penyangga tidak dapat dipisahkan dengan analisa pembuatan rekomendasi sistem penyangga sebagai langkah awal dalam merancang memilih berbagai jenis penyangga pada tambang bawah tanah. Tujuan dari penelitian ini untuk mengetahui tipe kelas batuan, menentukan ground support recommendation dari sistem RMR dan mengetahui faktor keamanan lubang bukaan. Metode dalam penelitian ini dilakukan langsung di lapangan dan data tersebut di olah dalam beberapa persamaan rumus yang nantinya untuk melihat jumlah baut batuan yang dibutuhkan dalam pemasangan penyangga dan setelah semua data telah terkumpul dilakukan analisa pemodelan menggunakan sofwere phase2 untuk melihat kestabilan lubang bukaan setelah dilakukan pemasangan penyangga. Berdasarkan klasifikasi geomekanik, massa batuan di decline Cikoneng untuk kuat tekan berkisar $2,86 \mathrm{Mpa}$ (point load index), RQD rata-rata $72 \%$ (sedang), spasi discontinuity total 1-3 m, kondisi diskontinuity dengan rating 23 point, kondisi air tanah dengan nilai bobot 7 (basah-menetes), orientasi discontinuity rata-rata memiliki faktor terkoreksi -3,64. Setelah dilakukan perhitungan dengan menggunakan beberapa rumus persamaan didapat 3 jenis penyangga dengan RMR yang berbeda-beda serta hasil pemodelan menggunakan sofwere phase2 diperoleh total perpindahan batuan sebelum penyangga $0,000187088 \mathrm{~m}$ dan setelah pemasangan penyangga menjadi 0,000176672 $\mathrm{m}$. kondisi batuan daerah penelitian termasuk dalam kelas III dengan tipe batuan sedang (RMR 54), GSR tipe 1 RMR $>51$, GSR tipe 2 RMR 41-50, GSR tipe 3 RMR $<40$, serta faktor keamanan naik menjadi 1,83 yang sebelumnya tanpa penyangga 1,30 .
\end{abstract}

Kata Kunci : Geomekanik, penyanggaan, RMR, pemodelan, Phase2.

\begin{abstract}
Underground mine geotechnical is one way to analyze the stability of underground mine openings in determining the supporting system and discuss the supporting system can not be separated from the analysis of making recommendations supporting system as the first step in designing choose different type of supporting in underground mines. The purpose of this study to determine the type of rock class, determine ground support recommendation from RMR system and know the safety factor openings. The method in this research is done directly in the field and the condition of discontinuous, the of ground water, the orientation of discontinuous, the is processed in some equation formula that will to see the amount of rock bolt required in the installation of supporting and after all the data has been collected analyzed using softwere Phase2 modeling to see the stability of the openings after installing supporting. Based on geomechanics classification, the rock mass in decline Cikoneng for compressive strength range of $2.86 \mathrm{MPa}$ (point load index), average RQD $72 \%$ (medium), discontinuity total of 1-3 m spacing, discontinuity condition with a rating of 23 points, the water conditions ground with the weight value 7 (wet-dripping), the orientation of the average discontinuity have corrected factor -3.64. After calculation using several equations obtained 3 types of supporting with different RMR as well as the modeling results obtained using Phase 2 softwere total displacement supporting $0.000187088 \mathrm{~m}$ rock before and after installation of a supporting into $0.000176672 \mathrm{~m}$. rock conditions research areas included in the third class with the type of rock being (RMR 54), GSR type 1 RMR $>51$, GSR type 2 41-50 RMR, RMR GSR type $3<40$, as well as the safety factor rose to 1.83 previously without 1.30 .
\end{abstract}

Keywords: Geomechanics, Supporting, RMR, modeling, Phase2. 


\section{PENDAHULUAN}

Ground Support Recommendation adalah rekomedasi untuk membuat sistem penyangga berdasarkan data-data yang telah didapatkan langsung di lapangan untuk mendukung dalam kerja satuan geoteknik. pembahasan mengenai sistem penyanggaan batuan merupakan bagian ilmu penting dalam tambang bawah tanah yang tidak dapat terpisahkan dari pembahasan mengenai metode penambangan bawah tanah. Pembahasan ini juga menjadi sangat penting mengingat karakteristik batuan yang berbedabeda dan memungkinkan munculnya bidang lemah batuan yang menyebabkan terjadinya ketidakstabilan batuan seperti terjadinya runtuhan sehingga menghambat kerja perusahaan dan berakibat pada terhambatnya pencapaian tingkat produksi yang diinginkan. Penyanggaan sendiri didefinisikan sebagai sistem yang membantu batuan agar dapat menopang dirinya sendiri sehingga mencapai keseimbangan setelah padanya diberikan gangguan berupa lubang bukaan.

Maksud dari penelitian ini adalah mempelajari cara membuat rekomendasi penyagga berdasarkan klasifikasi sistem RMR.

Tujuan dari penelitian ini adalah mengetahui tipe kalas batuan, menentukan ground support recommendation dari sistem RMR dan mengetahui safety faktor lubang bukaan.

\section{METODOLOGI PENELITIAN}

Metode yang digunakan dalam penelitian ini adalah dengan menggunakan metode penelitian langsung lapangan.

Metode penelitian lapangan dilakukan dengan cara melakukan pengambilan data hasil mapping geotek pada daerah penelitian secara langsung. Pada tahapan ini data yang diambil yaitu data rock condition, data rock strength, data rock quality designation, data spasi of diskontinyu, data condition of diskontinyu, data ground water, data orientasi of diskontinyu.

Data - data yang telah diperoleh dari lapangan selanjutnya di olah dengan menggunakan metode statistik untuk mendapatkan nilai RMR terkoreksi serta analisis kestabilan lubang bukaan dengan softwere phase2. data yang di dapatkan di lapangan juga di olah dengan menggunakan beberapa rumus, untuk bahan masukan dalam merekomendasi sistem penyangga agar didapat sistem penyagga yang efektif dan efesien.

Adapun rumus-rumus yang digunakan adalah:
RQD (Priest \& Hudson, 1976):

$R Q D=100 e^{-0,1 \lambda}(0,1 \lambda+1)$

$\lambda=\frac{L}{N}$

Dimana $: \lambda=$ Frekuansi diskontinyu

$\mathrm{L} \quad=$ Jumlah kekar

$\mathrm{N}=$ Panjang Scanline

Perhitungan ht, Prmr dan P (Unal, 1983) :

$\mathrm{ht}=\frac{100-\mathrm{RMR}}{\mathrm{B}} \mathrm{B}$

100

$\mathrm{P}_{\mathrm{RMR}}=\frac{100-\mathrm{RMR}}{100} \times \mathrm{B} \times \gamma$

$\mathrm{P}=\mathrm{B} \cdot \mathrm{c} \cdot \mathrm{P}_{\mathrm{RMR}}$

Dimana:

$$
\begin{array}{ll}
\mathrm{ht} & =\text { Tinggi runtuh }(\mathrm{Ton} / \mathrm{m} 2) \\
\operatorname{Prmr} & =\text { Baban runtuh }(\mathrm{m}) \\
\mathrm{P} & =\text { Beban luas atap }(\text { Ton }) \\
\mathrm{B} & =\text { Lebar terowongan }(\mathrm{m}) \\
\gamma & =\text { Densitas batuan }
\end{array}
$$

Perhitungan jumlah rock bolt (Camel \& Biron, 1983).

$$
\mathrm{n}=\frac{\text { B.ht.c. } \gamma \cdot \mathrm{FK}}{\mathrm{R}_{\max }}
$$

$\mathrm{s}=\underline{\mathrm{B}}$

$\mathrm{n}$

Dimana:

$$
\begin{array}{ll}
\mathrm{n} & =\text { Jumlah rock bolt }(\mathrm{pcs}) \\
\mathrm{B} & =\text { Lebar terowongan }(\mathrm{m}) \\
\mathrm{ht} & =\text { Tinggi runtuh }(\mathrm{m}) \\
\mathrm{c} & =\text { Panjang Bukaan }(\mathrm{m}) \\
\mathrm{Rmax} & =\text { kemampuan tarik (Ton) } \\
\mathrm{FK} & =\text { Faktor keamanan } \\
\gamma & =\text { Densitas batuan } \\
\mathrm{s} & =\text { Spasi rock bolt }(\mathrm{m})
\end{array}
$$

Perhitungan ketebalan shotcrete (Biron \& Arioglu, 1983):

$$
\delta=0,434 \quad \underline{\mathrm{P}_{\mathrm{RMR}} . \mathrm{B}}
$$

$\mathrm{T}$

$$
\mathrm{T}=0,2 \frac{\textrm{B}}{\mathrm{FK}}
$$


Dimana:

$$
\begin{array}{ll}
\delta & =\text { Ketebalan shotcrete }(\mathrm{m}) \\
\operatorname{Prmr} & =\text { Baban runtuh }(\mathrm{m}) \\
\mathrm{B} & =\text { Lebar terowongan }(\mathrm{m}) \\
\mathrm{T} & =\text { shear stress shotcrete }(\mathrm{Ton} / \mathrm{m} 2) \\
\mathrm{LB} & =\mathrm{UCS} \text { shotcrete }(\mathrm{Ton} / \mathrm{m}) \\
\mathrm{FK} & =\text { Faktor keamanan }
\end{array}
$$

\section{HASIL DAN PEMBAHASAN}

Lokasi yang digunakan sebagai tempat penelitian adalah daerah decline Cikoneng, decline Cikoneng merupakan area development dari salah satu tambang Cibaliung. Area ini memiliki bukaan sebesar 4,2 x 4,8 meter. Decline Cikoneng berada di level 116 meter dan merupakan bagian foot wall dari tambang Cikoneng.

\section{Klasifikasi sistem RMR}

Rock mass rating sistem atau dikenal dengan metode geomechanichs clasification di kembangkan oleh Bieniawski pada tahun 19721973. Metode klasifikasi RMR merupakan metode yang sederhana dalam penggunaannya dan parameter-parameter yang digunakan dapat diperoleh baik dari data lubang bor maupun dari pemetaan geoteknik struktur bawah tanah. Berikut ada lima paremter yang digunakan untuk mengklasifikasikan massa batuan dengan sistem RMR:
a. Kuat tekan uniaksial batuan utuh
b. Rock Quality Designation
c. Spasi bidang diskontinyu
d. Kondisi bidang diskontinyu
e. Kondisi air tanah
f. Orientasi bidang diskintinyu

Berdasarkan hasil pembobotan parameter di atas maka didapat rata-rata nilai RMR sebagai berikut:

Tabel 1. Hasil pembobotan nilai RMR

\begin{tabular}{|c|c|c|c|c|}
\hline No & Tanggal & $\begin{array}{c}\text { Kemajuan } \\
(\mathrm{M})\end{array}$ & $\begin{array}{c}\text { Span } \\
(\mathrm{M})\end{array}$ & RMR \\
\hline 1 & 19 -Sep-15 & 1,5 & 4 & 52,7 \\
\hline 2 & 21 -Sep-15 & 1,3 & 4 & 58,2 \\
\hline 3 & 24 -Sep-15 & 1 & 4 & 55 \\
\hline 4 & 26 -Sep-15 & 1,3 & 4 & 56,9 \\
\hline 5 & 27 -Sep-15 & 1,5 & 4 & 51,4 \\
\hline 6 & 29 -Sep-15 & 1,3 & 4 & 53,8 \\
\hline 7 & 30 -Sep-15 & 1,2 & 4 & 55,9 \\
\hline 8 & 1 Okt 15 & 1,2 & 4 & 52,2 \\
\hline 9 & 08 okt 15 & 1,3 & 4 & 54,7 \\
\hline 10 & 10 okt 15 & 1 & 4 & 60,8 \\
\hline 11 & 11 okt 15 & 1,3 & 4 & 55,2 \\
\hline 12 & 12 okt 15 & 1,6 & 4 & 51,4 \\
\hline 13 & 14 okt 15 & 1 & 4 & 53,8 \\
\hline 14 & 15 okt 15 & 1,3 & 4 & 55,3 \\
\hline 15 & 17 okt 15 & 1,6 & 4 & 54,1 \\
\hline
\end{tabular}

Tabel diatas menunjukan nilai rata-rata decline Cikoneng adalah RMR 54.

\section{Penentuan ht, Prmr dan P}

Berdasarkan rumus ht, Prmr dan $\mathrm{P}$ pada metode penelitian di dapat hasil sebagai berikut:

Tabel 2. Hasil perhitungan ht, Prmr dan P

\begin{tabular}{|c|c|c|c|c|c|}
\hline NO & $\begin{array}{c}\text { Span } \\
(\mathrm{M})\end{array}$ & RMR & $\begin{array}{c}\text { HT } \\
(\mathrm{M})\end{array}$ & $\begin{array}{c}\text { Prmr } \\
(\text { Ton/M2) }\end{array}$ & P (Ton) \\
\hline 1 & 4 & 52,7 & 1,892 & 4,9192 & 29,5152 \\
\hline 2 & 4 & 58,2 & 1,672 & 4,3472 & 22,60544 \\
\hline 3 & 4 & 55 & 1,8 & 4,68 & 18,72 \\
\hline 4 & 4 & 56,9 & 1,724 & 4,4824 & 23,30848 \\
\hline 5 & 4 & 51,4 & 1,944 & 5,0544 & 30,3264 \\
\hline 6 & 4 & 53,8 & 1,848 & 4,8048 & 24,98496 \\
\hline 7 & 4 & 55,9 & 1,764 & 4,5864 & 22,01472 \\
\hline 8 & 4 & 52,2 & 1,912 & 4,9712 & 23,86176 \\
\hline 9 & 4 & 54,7 & 1,812 & 4,7112 & 24,49824 \\
\hline 10 & 4 & 60,8 & 1,568 & 4,0768 & 16,3072 \\
\hline 11 & 4 & 55,2 & 1,792 & 4,6592 & 24,22784 \\
\hline 12 & 4 & 51,4 & 1,944 & 5,0544 & 32,34816 \\
\hline 13 & 4 & 53,8 & 1,848 & 4,8048 & 19,2192 \\
\hline 14 & 4 & 55,3 & 1,788 & 4,6488 & 24,17376 \\
\hline 15 & 4 & 54,1 & 1,836 & 4,7736 & 30,55104 \\
\hline
\end{tabular}

Tabel di atas sebagai patokan dalam menentukan banyaknya jumlah rock bolt yang akan digunakan dalam pemasangan penyangga batuan.

\section{Penentuan jumlah rock bolt dan ketebalan shorcrete}

Berdasarkan hasil perhitungan jumlah rock bolt dan ketebalan shotcrete pada rumus di metode penelitian di dapat hasil pada tabel dibawah ini:

Tabel 3. Hasil perhitungan jumah rock bolt dan ketebalan shotcrete

\begin{tabular}{|c|c|c|c|c|}
\hline NO & $\mathrm{n}(\mathrm{Pcs})$ & $\mathrm{S}(\mathrm{m})$ & $\begin{array}{c}\text { Panjang } \\
\text { rock bolt }(\mathrm{m})\end{array}$ & $\begin{array}{c}\text { Shotcrete } \\
\Delta(\mathrm{m})\end{array}$ \\
\hline 1 & 10 & 1,2 & 2 & 0,026 \\
\hline 2 & 8 & 1,5 & 2 & 0,023 \\
\hline 3 & 7 & 1,7 & 2 & 0,025 \\
\hline 4 & 8 & 15 & 2 & 0,024 \\
\hline 5 & 11 & 1,1 & 2 & 0,027 \\
\hline 6 & 9 & 1,3 & 2 & 0,026 \\
\hline 7 & 8 & 1,5 & 2 & 0,024 \\
\hline 8 & 8 & 1,5 & 2 & 0,026 \\
\hline 9 & 9 & 1,3 & 2 & 0,025 \\
\hline 10 & 6 & 2 & 2 & 0,022 \\
\hline 11 & 9 & 1,3 & 2 & 0,025 \\
\hline 12 & 11 & 1,1 & 2 & 0,027 \\
\hline 13 & 7 & 1,7 & 2 & 0,026 \\
\hline 14 & 9 & 1,3 & 2 & 0,025 \\
\hline 15 & 11 & 1,1 & 2 & 0,025 \\
\hline
\end{tabular}

Tabel diatas menunjukkan jumlah rock bolt dan ketebalan shotcrete yang berbeda-beda, ini di 
sebabkan nilai RMR setiap peledakan tidaklah sama.

\section{Groung Support Recommendation (GSR) bedasarkan nilai RMR}

Berdasarkan hasil dari semua perhitungan maka dalam penelitian ini peneliti sendiri membagi ground support recommendation menjadi tiga tipe jenis penyangga berdasarkan nilai RMR yang telah didapatkan dari 6 pembobotan. Adapun pembagian tipe penyangga dari sistem nilai RMR yaitu tipe $1 \mathrm{RMR}>51$, tipe 2 RMR 41-50 dan tipe 3 RMR $<40$.

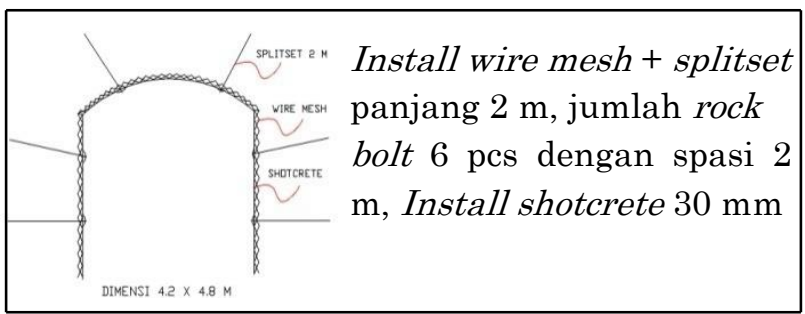

Gambar 1. GSR Tipe 1 RMR $>51$

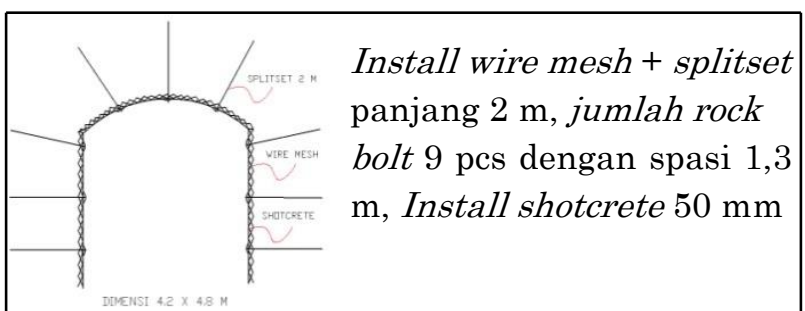

Gambar 2. GSR Tipe 2 RMR 41-50

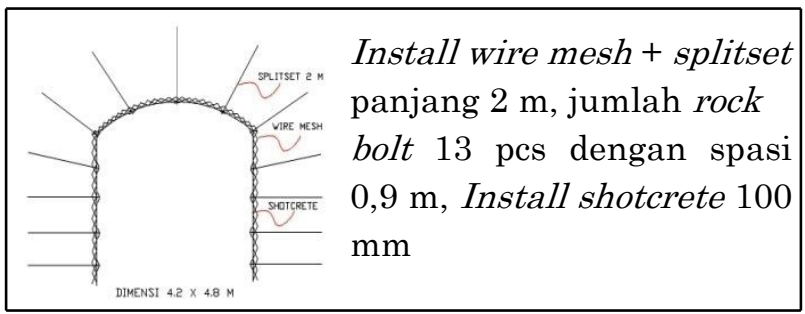

Gambar 3. GSR Tipe 3 RMR $<40$

\section{Pemodelan lubang bukaan menggunakan phase2}

Pemodelan penyanggaan lubang bukaan dilakukan dengan tujuan mengetahui keadaan batuan yang ada setelah di excavasi.

Setelah model dan seluruh parameter analisis dimasukkan, pemodelan kemudian di compute dan hasil analisis keluar sabagai gambar berikut:
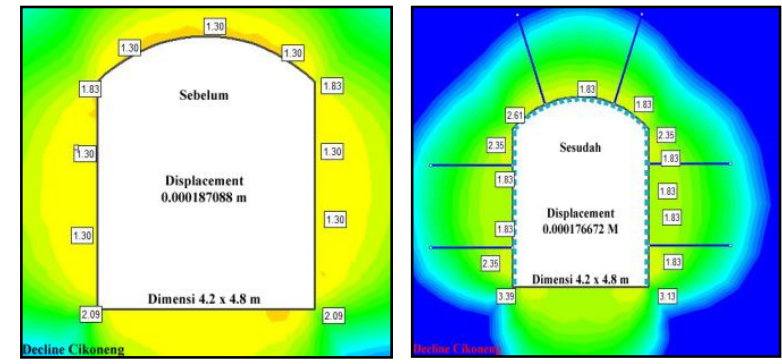

Gambar 4. Hasil Interpret phase2 decline Cikoneng

Analisis pemodelan phase 2 pada decline Cikoneng dapat dilihat pada tabel dibawah ini:

Tabel .4 Total Displacement dan FK decline Cikoneng

\begin{tabular}{|c|c|c|}
\hline \multirow{2}{*}{ Lokasi } & \multicolumn{2}{|c|}{$\begin{array}{c}\text { Total Displacement dan FK } \\
\text { (meter) }\end{array}$} \\
\cline { 2 - 3 } & $\begin{array}{c}\text { Tanpa } \\
\text { Penyanggaan }\end{array}$ & install Shotcrete \\
\hline Decline & $0,000187088 /$ & $0,000176672 /$ \\
Cikoneng & FK 1,3 & FK 1,83 \\
\hline
\end{tabular}

\section{KESIMPULAN}

Berdasarkan hasil pengamatan, perhitungan, dan pembahasan pada bab - bab sebelumnya, dapat di simpulkan :

Berdasarkan klasifikasi Geomekanika, kondisi batuan daerah penelitian termasuk dalam kelas III dengan tipe batuan sedang (RMR 54), GSR tipe 1 RMR $>51$, GSR tipe 2 RMR 41-50, GSR tipe 3 RMR <40, serta faktor keamanan naik menjadi 1,83 yang sebelumnya tanpa penyangga 1,30 .

\section{UCAPAN TERIMAKASIH}

Penulis mengucapkan terima kasih kepada semua pihak terutama :

1. Bapak Urip Ahmad subekti selaku Kepala Departemen Quality Control PT. Cibaliung Sumberdaya.

2. Seluruh satuan kerja geoteknik yang telah banyak membantu dan membimbing kami selama penelitian.

\section{DAFTAR PUSTAKA}

Bieniawski, Z.T. 1989. Enggineering Rock MesS Classification. New York. Wiley

Biron and Ariogle, 1983. Design of Support in Miners. New York. Inc 
Camel and Biron, 1983. Support Tunneling of the Geology. Canada. Jonk Wiley \& sonk Inc.

Priest, S.D,. Hudson, J.A.1976. Discontinuity Spacing in Rock Geomechaniest Abstrack. Rotterdam. Balkema.

Unal, 1983. The Empirical Rock Load Height Equation. Usa. Numerical studies. 